\title{
Research On The Reliability Of Henan Electric Power Communication Network Security And The Application Of PTN Technology
}

\author{
Li Xiong ${ }^{1 . a}$, Liang Si-xiang ${ }^{2}$, Lu Ji-zhao ${ }^{1}$, Luo Bin ${ }^{1}$, Wang Shi-wen ${ }^{1}$, Liu Bo ${ }^{1}$ \\ ${ }^{1}$ Information\& Telecommunication Co. of State Grid Henan Electric Power Company, Zhengzhou \\ 450052 China \\ ${ }^{2}$ Informational Engineering Department of Zhengzhou University, Zhengzhou 450001 China \\ aelf8650@163.com
}

Keywords: electric power communication, network security, PTN technology

\begin{abstract}
In order to ensure the safety of electric power monitoring system and communication network, PTN (Packet Transport Network, Packet transmission Network) technology is introduced to meet the new needs of electric power communication Network. In this paper, the current situation of Henan electric power communication network was analyzed and then the application of PTN technology in Henan Power System was also discussed.
\end{abstract}

\section{Introduction}

Electric power communication network is an important means to ensure security, stability and economic operation of power grid, also is the basis to set up intensive and highly efficient modern electric power enterprise. With the advancement of electric power information construction and the enhancement of electric power dispatching automation level all kinds of production and management information is becoming diversified and developing in the direction of ALL IP. In order to ensure the safety of electric power monitoring system and electric power dispatching data network, grid business is divided into production control district and management information regions. Production control district is divided into controlled area (Zone I) and uncontrolled area (Zone II); When management information regions without affect the safety of production control regions can be divided into information business area (zone III) and office business area (zoneIV)according to different safety requirements[1-2].Production control district and Management information regions can realize security isolation in the physical plane.PTN communication network need carrying out the physical isolation for different safety zones' business and realizing logic isolation between safety zone[3]. In this paper, the current situation of Henan electric power communication network was analyzed and then the application of PTN technology in Henan Power System was also discussed.

\section{The Current Conditions of Henan Electric Power Communication Network}

Electric power communication system has many different kinds of business. With the constant improvement of dispatching automation and enterprise management level, the arrival of network information age, the present of UHV power grid, transmitting electricity from west to east, three-vertical and three-horizontal, Hazheng DC, electric power and electric network is tend to modernization, intelligent variety. Electric power and electric network puts forward higher requirement on power communication service. According to the research report of national grid smart grid Communications Ministry published, it is concluded that electric power communication 
network has the following common problems by investigation and analysis Henan electric power communication network.

Electric Power Communication Network Structure Is Weak. Communication network technology transmission cost is very big. Network structure is not reasonable and poor extensibility. Early electric power communication transmission of cities is formed in the backbone layer in order to meet the various needs of the business. But electric power communication branch tend to adopt a tree combined with a ring of two-stage complex network structure, it is difficult to constitute detour of whole circuit.

Main line Transmission Capacity Is Insufficient. Electric power communication network is used in the electric power dispatching and internal telephone communication in terms of data business support. Communication network trunk circuit capacity generally only has $10 \mathrm{~Gb} / \mathrm{S}$ and $2.5 \mathrm{~Gb} / \mathrm{S}$, a few is $622 \mathrm{MB} / \mathrm{S}$ and the $155 \mathrm{MB} / \mathrm{S}$. Capacity insufficient seriously restrict the development and access of new business with the development diversity of data business and the increase of bandwidth demand[4]

Communication Equipment Is Fall Behind, Part of the Main Line Exceed the Time Limit Seriously. Henan transmission network is using SDH transmission system. Many equipment have been running more than 15 years, they need update. In the use of network resources of square face, Henan transmission network also hasn't real-time control function in using network resource. it is difficult to ensure the Quality of Service (QoS) by calculating optimal allocation of resources if can't real-time and dynamic adjust logical topology structure of network.

Communication technology network scalability and interoperability is not good in terms of the interconnection with other.

\section{The Solution and Application of PTN Technology}

Local power grid investment is different in electric power communication network due to different development level. Grid developed area, the equipment has achieved digital ring network and has ability to provide power grid communication service; Grid undeveloped area even the most basic phone service cannot be guaranteed. For example, Xinxiang Yuanyang country area basic telephone service still rely on carrier wave for transmission, they could not interconnect with other area. The cities and counties in these areas have many problems on interconnect, urban carrier communication equipment has been eliminated, cities and counties should not hybrid networking. Several counties have different equipment manufacturers, equipment rate is not specification, equipment operational is bad, so the electric power communication network has been stagnation, which is the "bottleneck" of electric power communication network development.

Regional communication transmission network of Henan electric power corporation is local dispatching information collection and business transmission important support platform which was founded before and after 2000. With "three sets of five major" system construction and the development of smart grid, County grid "dispatch and control Unity", the information system completes coverage, Video business development into town makes data service growth quickly, Regional Communication transmission network structure (can't meet the demand of cities and counties integration), transmission capacity(Unable to adapt the rapid development of data service) and equipment operation status (partial model equipment unproduced, spare parts difficult) all have different problems. To solve above problem, Henan electric power company relevant personnel have analysis relevant communication technology and further research Shandong Electric Power and public network operators (Mobile, Unicom, Telecom) communication network construction 
experience. finally take the SDH+PTN their networking scheme for regional transmission network to undertake transforming. On the basis of comparing SDH, MSTP, PTN, Router Networking relevant technology and together with the construction present situation of Henan electric power company transmission network, finally we take the program of SDH+PTN Networking respectively to transform regional transmission network.

PTN equipment networking should use hierarchical structure considering the characteristics of the electric power communication network [5].Regional network structure can be divided into three layers: Access Layer, Convergence Layer, Backbone Layer. Access Layer uses double nodes star accessing topology. Convergence Layer uses double nodes hanging ring structure to prevent single node failure of convergence layer nodes and backbone nodes. Backbone layer no longer builds ring system, but it connects with convergence layer directly through GE or $10 \mathrm{~Gb}$ Ethernet link. At the same time, in each backbone room configures two sets large-scale PTN equipment to take charge of equipment port accessing, business scheduling, and implement sharing responsibility for safety.

Under the condition of electric power communication network has been formed, PTN transmission network cannot complete immediately, we should base on the present situation and development trend of network building SDH and PTN network gradually and finally forming the PTN network independently. This process can be divided into three stages.

First stage: early construction. IP business have sporadic access requirement in access layer. The introduction of PTN equipment mainly concentrate in the access layer, PTN equipment and SDH equipment make up SDH mixture ring to provide E1, FE and other business accessing. In hybrid networking, IP business transmission capacity is limited and can't play the advantage of PTN kernel IP-based, because PTN equipment must give consideration to SDH function. This period can accumulate rich engineering construction and equipment operational management experience for large-scale PTN construction.

The second stage: middle construction. With the continuous progress of electric power modernization construction, more and more IP business need to access. Business developed areas will form GE ring which is built by PTN alone. Considering the demand of some rendezvous points hanging GE access ring, convergence layer related nodes (e.g., E, F) can be replaced with PTN through MSTP directly or gradually, its purpose is to make such nodes have access capability of GE ring.

The third stage: mature stage. The goal of power modernization is all kinds of business information, such as voice, data, image, realizing IP-based and convergence layer and access layer all making up with PTN equipment. Management maintenance work will be greatly simplified, operation maintenance cost will be greatly compression, network input and output ratio will be greatly increased after completing this stage construction. Communication business development has clearly showed the trend of IP-based under the background of power information construction. PTN as a new technology of transport and grouping technology integration, its advantage of bearing IP business is very obvious. In the future construction of power communication network PTN will play an important role and will gradually become a new generation mainstream transmission technology.

\section{Conclusion}

With the advancement of electric power information construction and the enhancement of electric power dispatching automation level, PTN (Packet Transport Network, Packet transmission Network) technology meets the new needs of electric power communication Network.PTN is a kind of 
general cross technology which is block-oriented. It has the advantages of SDH/MSTP transmission network such as good scalability, rich operation and maintenance function and fast protection switching, at the same time it also increases many suitable characteristics for data service transmission such as packet switching, statistical multiplexing, connection-oriented label switching, grouping QoS mechanism and control surface flexible. In this paper, the current situation of Henan electric power communication network was analyzed and then the application of PTN technology in Henan Power System was also discussed.

\section{References}

[1] YIN Hong-xia, HAN Dao-guang, WU Ding-hui, XUAN Ran-ran. Introduction to PTN technology application in the electric power communication network[J]. China New Telecommunications, 2014,14.

[2] PENG Bo-tao. The application of PTN technology in the electric power communication network[J]. Electric Power Technology, 2010,9.

[3] AN Xue-jun .Planning and Design of Power Electric Communication Network in Xinxiang Based on PTN Technology[D]. Xian university of electronic science and technology, 2014,5.

[4] JIA Xiao-tie, LEI Xue-yi, WU Yun-feng, LI Wei-hua. PTN Provides an Ideal Information Platform for Smart Grid[J]. Telecommunications for Electric Power System, 2010,7(31):213-215.

[5] WANG Liang. PTN technology and its application research[J]. Nanjing university of posts and telecommunications[D]. Nanjing university of posts and telecommunications, 2013,5. 